\title{
A COMPARATIVE ANALYSIS OF VOLATILITY MODELS IN SOME EMERGING STOCK EXCHANGES
}

\author{
Jesús Téllez Gaytán* \\ Departamento de Finanzas \\ Tecnológico de Monterrey, Campus Estado de México \\ Pablo López Sarabia \\ Departamento de Finanzas \\ Tecnológico de Monterrey, Campus Estado de México
}

(Received 22 March 2005, accepted 8 June 2005)

\begin{abstract}
This document compares volatility of Mexico, Brazil, and Argentina stock exchanges under GARCH models during the 1990's financial crises. On an intra-market approach, the IPyC was more volatile during the Asian financial crisis. On an inter-market approach, Bovespa showed to be the most volatile during the period of study. The IPyC index shows that whenever returns drop the effect on the conditional volatility is greater in a bullish market. This asymmetric pattern was captured on the spread between the TGARCH and GARCH values and it shows that negative returns have been dominating positive ones besides the existence of bullish markets.
\end{abstract}

\section{Resumen}

Este documento compara la volatilidad entre los índices accionarios de México, Brasil y Argentina a través de los modelos de volatilidad GARCH durante las crisis financieras de los noventa. En un enfoque intra-mercado, el IPyC mostró ser el más volátil en la crisis financiera asiática. En un enfoque inter-mercado, el Bovespa mostró la volatilidad más alta en el periodo de estudio. El IPyC mostró que siempre que los rendimientos caen, el efecto en la volatilidad condicional es mayor durante un mercado alcista. Este comportamiento asimétrico es capturado en las diferencias de las series TGARCH y GARCH, y muestra que rendimientos negativos han dominado a los positivos a pesar de un mercado alcista.

JEL classification: C32, G10

Keywords: Volatility, Financial Crisis, Heteroskedasticity

* Departamento de Finanzas, Tecnológico de Monterrey, Campus Estado de México, Carretera Lago de Guadalupe, Krn. 3.5, Atizapán de Zaragoza, Estado de México, c. p. 52929, México. Telephone: +52(55)5864 5555. E-mails: jctellez@itesm.mx and plopezs@itesm.mx 


\section{Introduction}

Since the last decade there has been an increasingly and used of volatility models in order to understand and explain economic and financial variability series. Conventional time series and econometric models uses constant variance but evidence has shown that variance on long-run periods seems to be nonconstantly. One of the first conditional volatility models was developed by Engle (1982) who introduced an ARCH model that describes the conditional variance which stands for autoregressive conditional heteroskedasticity.

The ARCH model basically assumes that the variance of tomorrow's return is an equally weighted average of the squared residuals of the last periods and this model lets the weights be parameters to be estimated. A generalization of the ARCH model is the GARCH parametrization introduced by Bollerslev (1986). The main characteristic of GARCH models is that it has declining weights that never go completely to zero. The GARCH model asserts that the best predictor of the variance in the next period is a weighted average of the long-run average variance, the variance predicted for this period, and the new information in this period that is captured by the most recent squared residual.

The usefulness of conditional volatility models has been especially in analyzing financial data since it has been observed an amplitude of the returns which varies over time described as "volatility clustering".

This document makes a comparative analysis of volatility models among important American emerging stock markets as Mexico, Argentina and Brazil, during the 1990's financial crises. We use the GARCH conditional volatility and two important extensions as TGARCH and EGARCH in order to capture asymmetric effects of returns on the conditional volatility and prove whether or not negative returns have been dominating positive returns even in bullish markets. We aim to show and measure which country has been more affected by financial crises. The important purpose of this document is to answer: what is the importance of volatility in the basic nature of investments?

Other studies have investigated volatility in emerging markets and it has been found, as Aggarwal et al. (1999) did, that most events tend to be local and only the October 1987 crash was a global event that caused a significant jump in the volatility of several emerging stock markets.

Others, Edwards and Susmel (2000), have shown that there is a strong evidence of volatility co-movements across countries especially among the MERCOSUR countries with no results of contagion stories. Patel and Sarkar (1998) concluded that there is a strong evidence of contagion within regions and those stock markets affected by the crisis are about equally affected, both in terms of the severity of the price decline and the duration of the crisis. They also stated that for short horizons, prices are autocorrelated, whereas for longer horizons there is evidence of mean reversion. Showing that over long horizons prices do recover from crash, but the recovery time is longer for emerging markets.

The document is organized as follows: the second section briefly describes the GARCH volatility models, sections three and four explain data and the methodology used to estimate the models. In section five we give the empirical results comparing each graph and estimation outputs. Finally section six concludes the empirical research. 


\section{Conditional Volatility Models}

\subsection{GARCH}

GARCH stands for Generalized Autoregressive Conditional Heteroskedasticity, which is a generalization of ARCH models. These models relax the hypothesis of constant volatility and introduce changes in volatility, which it means that the variance instead of being considered as homosedastic now it assumes to be heteroskedastic. The conditional variance in the model is the sum of the convex combination of the lagged squared shocks (errors) up to the $p$ lagged and a constant. This is how ARCH structure arises. The GARCH structure is an extension of the ARCH model that uses past variances and the past variance forecasts to forecast future variances.

The GARCH model stands for a conditional mean and variance equation. The mean equation or return model is:

$$
R_{t}=\mu+\varepsilon_{t}
$$

where the normal random variable $\varepsilon_{t}$, has a conditional variance $h_{t}$ given as:

$$
h_{t}=\alpha_{0}+\sum_{i=1}^{q} \alpha_{i} \varepsilon_{t-i}^{2}+\sum_{i=1}^{p} \beta_{i} h_{t-i}
$$

constraint to $p \geq 0 ; q>0 ; \alpha_{0}>0 ; \alpha_{1} \geq 0 ; \beta_{i} \geq 0$.

The GARCH process is of order $p \mathrm{y} q$, and the conditional variance equation is a function of three terms:

- The mean: $\omega$.

- News about volatility from the previous period, measured as the lag of the suqred residual from the mean equation: $\varepsilon_{t-i}^{2}$ (the $\mathrm{ARCH}$ term).

- Last period's forecast variance: $\sigma_{t-i}^{2}$ (the GARCH term).

A particular case is the GARCH $(1,1)$ which adjusts to a numerous series of asset returns. So the $(1,1)$ in $\operatorname{GARCH}(1,1)$ refers to the presence of a firstorder GARCH term and a first-order ARCH term. How is the $\operatorname{GARCH}(1,1)$ interpreted in a financial context? An agent can predict this period's variance by forming a weighted average of a long term average (the constant), the forecasted variance from last period (GARCH term), and information about volatility observed in the previous period (ARCH term).

Then a $\operatorname{GARCH}(1,1)$ model would be specified as:

$$
\begin{gathered}
R_{t}=\mu+\varepsilon_{t}, \\
h_{t}=\alpha_{0}+\alpha_{1} \varepsilon_{t-1}^{2}+\beta_{1} h_{t-1} .
\end{gathered}
$$

The conditional variance is estimated as:

$$
\sigma_{t}^{2}=\frac{\alpha_{0}}{1-\left(\alpha_{1}+\beta_{1}\right)}
$$




\subsection{TGARCH}

TGARCH or Threshold ARCH model also known as the GJR model, attempts to capture the presence of asymmetric behavior, specially when negative returns are related to a greater conditional variance rather than positive ones. This kind of asymmetries are typically attributed to leverage effects, whereby a fall in the value of a firm's stock causes the firm's debt to equity ratio to rise, leading to shareholders to perceive their future cashflow stream as being relatively more risky. It was first introduced by Zakoian (1990) and Gloste and Runkle (1993). The specification of the model is:

$$
\begin{gathered}
\dot{R_{t}}=\mu+\varepsilon_{t}, \\
h_{t}=\alpha_{0}+\alpha_{1} \varepsilon_{t-1}^{2}+\gamma \varepsilon_{t-1}^{2} d_{t-1}+\beta_{1} h_{t-1},
\end{gathered}
$$

where $d_{t-1}$ is a dummy variable that takes one if the return in $t-1$ is under its mean, and zero if the return is above the mean.

$$
d_{t-1}= \begin{cases}1 & \varepsilon_{t-1}<0 \\ 0 & \varepsilon_{t-1} \geq 0\end{cases}
$$

When $\varepsilon_{t-1}=R_{t-1}-\mu<0$ (good news), the conditional variance takes the value

$$
h_{t}=\alpha_{0}+\left(\alpha_{1}+\gamma\right) \varepsilon_{t-1}^{2}+\beta_{1} h_{t-1}
$$

and when $\varepsilon_{t-1}=R_{t-1}-\mu \geq 0$ (bad news), the conditional variance takes the value

$$
h_{t}=\alpha_{0}+\alpha_{1} \varepsilon_{t-1}^{2}+\beta_{1} h_{t-1} .
$$

In such case the variance is greater showing greater risk.

\subsection{EGARCH}

The EGARCH model stands for the exponential GARCH and it was proposed by Nelson (1991). The specification of the mean and conditional variance equation is:

$$
\begin{gathered}
R_{t}=\mu+\varepsilon_{t}, \\
\ln h_{t}=\omega+\beta \ln h_{t-1}+\alpha\left|\frac{\varepsilon_{t-1}}{\sqrt{h_{t-1}}}\right|-\alpha \sqrt{\frac{2}{\pi}}+\gamma \frac{\varepsilon_{t-1}}{\sqrt{h_{t-1}}} .
\end{gathered}
$$

In this case the effects of the errors on the conditional variance is an exponential type one and non-squared, then it can be written as

$$
h_{t}=h_{t-1}^{\beta} \exp \left[\omega+\alpha \frac{\left|\varepsilon_{t-1}\right|}{\sqrt{h_{t-1}}}-\alpha \sqrt{\frac{2}{\pi}}+\gamma \frac{\varepsilon_{t-1}}{\sqrt{h_{t-1}}}\right],
$$

where the variable

$$
z_{t}=\frac{\varepsilon_{t-1}}{\sqrt{h_{t-1}}}
$$


is a normal standardized variable, and the term $\sqrt{\frac{2}{\pi}}$ is the expected value of $\left|z_{t}\right|$.

It is observable that in an EGARCH model it is captured once again asymmetric behavior. If $\varepsilon_{t-1}=b>0$, the conditional variance is

$$
\ln h_{t}=\omega+\beta \ln h_{t-1}+(\alpha+\gamma) \frac{b}{\sqrt{h_{t-1}}}-\alpha \sqrt{\frac{2}{\pi}}
$$

If $\varepsilon_{t-1}=b \leq 0$ then the conditional variance is

$$
\ln h_{t}=\omega+\beta \ln h_{t-1}+(\gamma-\alpha) \frac{b}{\sqrt{h_{t-1}}}-\alpha \sqrt{\frac{2}{\pi}} .
$$

The essence of EGARCH models is that it allows to capture the exponential leverage effect rather than a quadratic form, and forecasts of the conditional variance are guaranteed to be nonnegative. The leverage effect can be tested by the hypothesis that $\gamma<0$, and there would be an asymmetric impact if $\gamma \neq 0$.

\section{Data}

The data consists of daily closed index values for the IPyC Index (Mexico), MERVAL (Argentina), and BOVESPA Stock Exchange Index (Brazil). It covers from January 1990 up to March 2003. It is important to note that the whole period does not match exactly each daily closed index value. In the case of IPyC Index it covers 3298 observations, MERVAL 3264, and BOVESPA 3248. This situation is presented because trading days are different in each stock market. Nevertheless this was not a rough source of constraint to estimate and compare volatilities since the differences in observations is insignificant compared to the whole historical data.

Daily values were transformed into daily returns and these were calculated in a basis of continuously returns, i.e. $R_{t}=\ln \left(P_{t} / P_{t-1}\right)$. The data was obtained from Economatica. We are just considering Latin American markets for we aim to compare which of the most important American emerging markets has been more sensitive to financial crises.

\section{Methodology}

As our aim is to detect and compare the volatility of returns in each financial crisis, firstly it was plotted each daily index value against its daily returns and locate in which period returns varied the most. Once detecting those most varying periods, they were compared each other in such a way to realize which market could result in the most volatile position.

After, GARCH estimations were done for each emerging market. This was performed in Eviews using the ARCH - Autoregressive Conditional Heteroskedasticity estimation method. In case of the GARCH model, the ARCH specifications were GARCH (symmetric), and the estimation options were the Marquardt optimization algorithm with starting coefficient values as OLS/TSLS. The maximum iterations specified were 200 . 
The $\operatorname{GARCH}(p, q)$ equation estimated and the conditional mean return model were of the form:

$$
\begin{gathered}
R_{t}=\mu+\varepsilon_{t} \quad \text { (conditional mean equation), } \\
h_{t}=\alpha_{0}+\sum_{i=1}^{q} \alpha_{i} \varepsilon_{t-i}^{2}+\sum_{i=1}^{p} \beta_{i} h_{t-i} \quad \text { (conditional variance equation). }
\end{gathered}
$$

It was estimated a $\operatorname{GARCH}(1,1)$, in which the conditional variance depends on a constant, the previous random shock (ARCH) and the conditional variance in the previous date (GARCH). It was assumed the following conditions: $\alpha_{0}>0$, $\alpha_{1} \geq 0 ;$ and $\beta_{1} \geq 0$.

$$
h_{t}=\alpha_{0}+\alpha_{1} \varepsilon_{t-1}^{2}+\beta_{1} h_{t-1} .
$$

Once the GARCH coefficients from the conditional variance equation were estimated, we proceed to calculate the non-conditional volatility value for each stock market return series. The non-conditional volatility is of the form:

$$
\sigma_{t}^{2}=\bar{\sigma}^{2}=\frac{\alpha_{0}}{1-\left(\alpha_{1}+\beta_{1}\right)} .
$$

In case of the TGARCH and EGARCH models, we used the TGARCH (asymmetric) and EGARCH as ARCH specifications respectively. For each model it was considered now the Heteroskedasticity Consistent Covariance option.

The TGARCH equation estimated and the conditional mean model were of the form:

$$
\begin{array}{cc}
R_{t}=\mu+\varepsilon_{t} & \text { (conditional mean equation), } \\
h_{t}=\alpha_{0}+\alpha_{1} \varepsilon_{t-1}^{2}+\gamma \varepsilon_{t-1}^{2} d_{t-1}+\beta_{1} h_{t-1} & \text { (conditional variance equation), }
\end{array}
$$

where $d_{t-1}$ is a dummy variable in which it takes a value of one if returns in the previous date are under its mean, and zero if returns are above its mean.

$$
d_{t-1}= \begin{cases}1 & \varepsilon_{t-1}<0 \\ 0 & \varepsilon_{i-1} \geq 0\end{cases}
$$

The EGARCH equation estimated and the conditional mean model were of the form:

$$
\begin{aligned}
R_{t} & =\mu+\varepsilon_{t} \\
\ln h_{t} & =\omega+\beta \ln h_{t-1}+\alpha\left|\frac{\varepsilon_{t-1}}{\sqrt{h_{t-1}}}\right|-\alpha \sqrt{\frac{2}{\pi}}+\gamma \frac{\varepsilon_{t-1}}{\sqrt{h_{t-1}}}
\end{aligned}
$$


For each estimation, we got the GARCH variance series. They were plotted only the GARCH series (as illustrated in figures from 4 to 6), and then it was taken and plotted the differences between the TGARCH and GARCH series. The TGARCH - GARCH differences indicate in which period positive returns dominate negative returns since the TGARCH model captures asymmetries in returns behavior. If the difference is positive on a certain period, then it is shown to be a downward phase in the market. Elsewhere when the difference is negative on a certain period, then it is shown to be an upward phase in the market.

Finally, on the each estimation output it was statistically tested the coefficient values of each parameter for each conditional volatility model. We focused on the value of the probability to be lower than a level of significance of 0.05 and we avoid the value of the determination coefficient $\left(R^{2}\right)$ since there are no regressors in the conditional mean equation. In case of the GARCH model it is expected to get positive signs in each of the estimated coefficients in the conditional variance equation and detect whether the sum of the GARCH and ARCH terms are near one. A sum closely to one assumes that shocks to the conditional variance would be highly persistent for each stock market series.

\section{Empirical Results}

Figure 1 plots Mexico IPyC's daily values and returns from January 1990 up to March 2003. Along this period the IPyC has been showing an upward trend and we can realize basically two periods in which the index value dropped, being those between September 1994 - March 1995 and November 1997 - May 1999. The decreasing in the index value also can be observed in a more variability of its returns in which during the first period the stock market had a negative return of about $5 \%$. In the second period it is shown two greater changes, both of them at the beginning of 1998 and 1999 respectively. In the first case, stock market returns dropped in almost $15 \%$ and in the second it showed a negative return of $10 \%$. These greater changes indicate the presence of high volatility derived from the financial crises.

Figure 2 plots Argentina MERVAL's daily values and returns. The pattern of trend that MERVAL holds does not show any upward movement, in some periods it goes up surprisingly but in others it seems to revert to a mean value. The greatest changes are shown in the MERVAL daily returns graph in which it is observed six major ones. The first one at the beginning of the 90 's, a second one between January 1991 - May 1991, a third one during the Mexican peso crisis, a fourth one during the Asian financial crisis (1997), a fifth one during the Russian default and the Brazilian real crisis (1999), and the sixth one between September $2001-2002$. As our aim is to compare volatility among the financial crises, so we are just interested in the two middle ones. In both periods it is observable the effects of the financial crises on the MERVAL performance. The worst negative return MERVAL index showed was almost of $20 \%$ at the beginning of the 90 's and later during the Asian financial crisis in about $15 \%$ and the Russian default in almost $14 \%$.

Figure 3 plots Brazil BOVESPA's daily values and returns. It is observable two trend patterns, the first one is an upward market trend from September 1993 to January 2000. The second pattern shows a downward market trend 
from February 2000 to January 2003. In these two periods we can distinguish three great drops of the BOVESPA value, each of them as a response from the financial crises. These changes are reflected on its daily returns series, showing that the greatest variability was during the Russian default and the Brazilian real crisis with a negative return of 18level of that from 2000 .

Those changes on the stock market returns are better observed in the GARCH Daily series graphs. These GARCH values were generated from the GARCH estimations for each emerging market and we can distinguish in each graph at least in our research period of interest, that volatility levels matches each financial crisis. Figure 4 shows the GARCH IPyC series and it is observable that during the Asian financial crisis the stock market return registered the greatest volatility level $(0.0045)$, followed by the Russian default and the Brazilian real crisis $(0.0035)$. As it shown, the lowest volatility level was that during the Mexican peso crisis (0.002). Figure 5 shows GARCH MERVAL series and it would seem that financial crises did not affect too much the stock market return, but the highest volatility $(0.0045)$ measured as the conditional variance was during the Russian default and the Brazilian real crisis followed by the Mexican pesos crisis, and the Russian default and Brazilian real crisis (0.004).

The BOVESPA was the most emerging stock market that suffered from financial crises. The stock market volatility is shown in Figure 6, in which during the Russian default showed a higher volatility (0.0145) than the Mexican peso crisis (0.013) and the Asian financial crisis (0.006).

Table 10 summarizes total volatilities for each stock market as the sum of the ARCH and the GARCH coefficients $\left(\alpha_{1}+\beta_{1}\right)$. The IPyC index presents the lowest total volatility (0.9490) during the decade of 1990 and the BOVESPA index shows the highest one (0.9977). As it was described above for each GARCH graph, the stock market with the greatest effects from financial crises was the BOVESPA. Also in Table 10 it is shown the non-conditional volatility for each stock market, and once again the BOVESPA index shows the greatest level $(0.0053)$ with respect to the other two indices. Tables 1 to 3 show the complete GARCH estimation outputs in which are shown that the coefficient values are highly statistically significant.

Since the three stock markets show different trends mostly downward ones and high volatility in their returns, this would let to arise a question: how is it possible to capture and measure differences between positive and negative returns when the market is bullish or bearish? It was estimated a TGARCH model that allows to capture asymmetric effects in order to determine how the conditional volatility is affected in a bullish market whenever returns drop. Table 11 summarizes the TGARCH estimation output for each stock market. All TGARCH coefficient values were highly statistically significant as shown in Tables 4 to 6 . The asymmetric effect is captured in the gamma coefficient and the highest value belongs to the IPyC index $(\gamma=0.1815)$. This implies that when IPyC returns drop, the effect on the conditional volatility is greater than in a bullish market. Although the gamma values for the MERVAL and BOVESPA indices are lower than the IPyC, it is shown that the TGARCH coefficient values are greater than the GARCH ones. This implies that along the historical indices returns, negative returns have dominated those positive 
ones besides the presence of bullish markets.

The asymmetric pattern can be observed on the differences between the TGARCH and GARCH values. Figures 7 to 9 show the differences for each stock index historical volatility returns. Besides these differences are insignificantly, it is observable that the IPyC index shows the greatest differences and deviations from its mean value. Once again there is evidence that whenever returns drop, the effect on the conditional volatility for the IPyC index is greater than a bullish market.

Finally it was estimated an EGARCH model in order to detect if negative shocks imply a higher next period conditional variance than positive shocks of the same sign. Tables 7 to 9 show the complete EGARCH estimation outputs. It was found that all the coefficient values were highly statistically significant and that the gamma coefficient truly takes a negative sign. Table 12 summarizes the estimation output and again the IPyC index showed the greatest gamma coefficient value.

Since the beginning we attempted to measure emerging stock market volatilities in order to identified which one resulted to be more sensitive, why is so important to measure volatility? Although we have estimated historical conditional and non-conditional volatilities, the volatility parameter is a measure of market risk and it was clearly, as shown on the estimation outputs, that each emerging stock market reacts in different ways to each financial crisis. Also, as the basic nature of the investment decision is return-risk trade-off, we must identified in which market and financial asset our investment is the most exposed to risk and in what level.

\section{Concluding Remarks}

In this document was proved that conditional volatilities models such as GAR$\mathrm{CH}$, TGARCH, and EGARCH, can be used to measure historical volatility in different emerging stock markets and it was possible to identified markets' behavior in each 1990's financial crisis.

BOVESPA index was the stock market among the IPyC and MERVAL indices to be the most volatile during the period of study. For this stock market the sum of the ARCH and GARCH terms was more closely to the unit, 0.9977 ; this means that shocks to the conditional variance are highly persistent on the BOVESPA index.

Although BOVESPA index showed to be more volatile than the other ones, IPyC index shows that whenever returns drop, the effect on the conditional volatility is greater than a bullish market. The TGARCH coefficient value showed to be greater than the GARCH coefficient value, then negative returns have been dominating positive ones besides the existence of bullish markets. The BOVESPA and MERVAL indices showed a larger TGARCH value with respect to the GARCH coefficient value.

The evidence shows that negative shocks in the IPyC index imply a higher next period conditional variance than positive shocks of the same sign. This phenomenon was captured on the gamma coefficient of the EGARCH volatility model. 
Finally, it was shown that each emerging stock market reacted in different ways to each financial crisis. The IPyC index was more volatile when the Asian financial crisis occurred; the MERVAL and BOVESPA indices were more volatile during the Russian default and the Brazilian real crisis. Just the BOVESPA index showed to be the most volatile stock market in the Mexican peso crisis.

Appendices: A. Figures

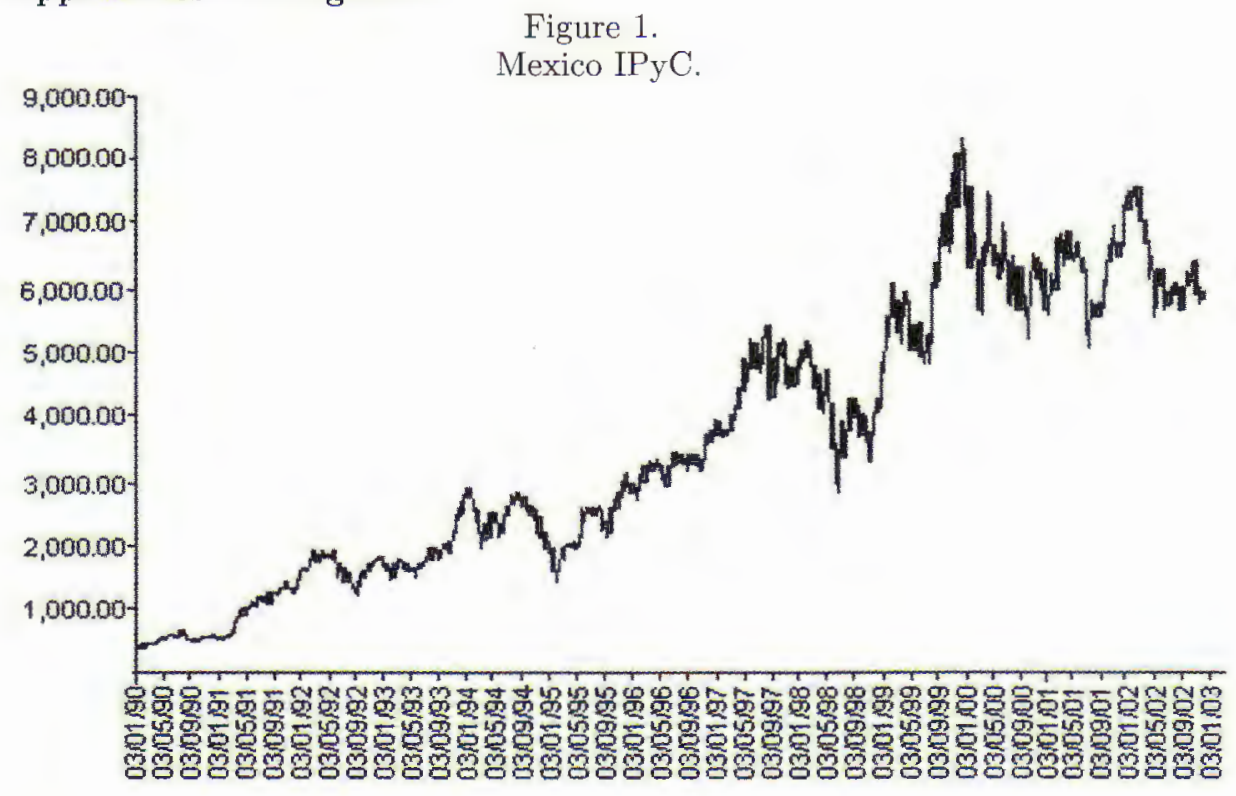

IPyC Daily Returns.

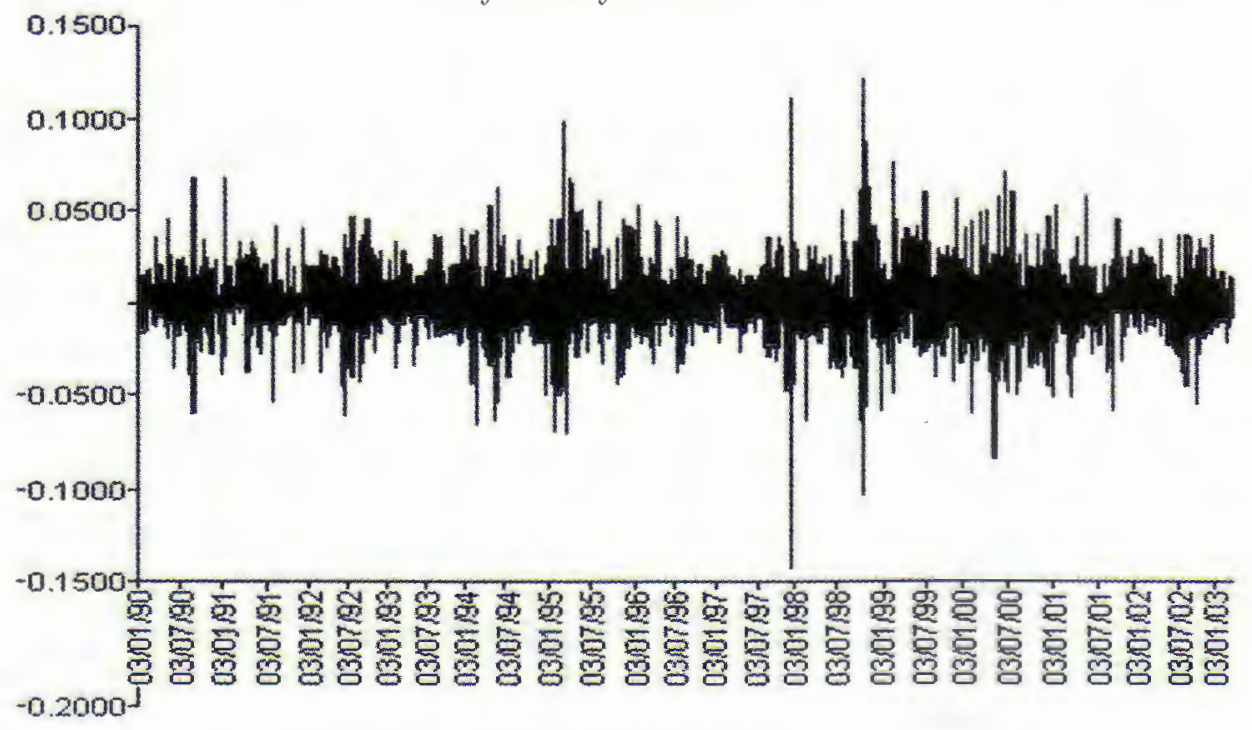



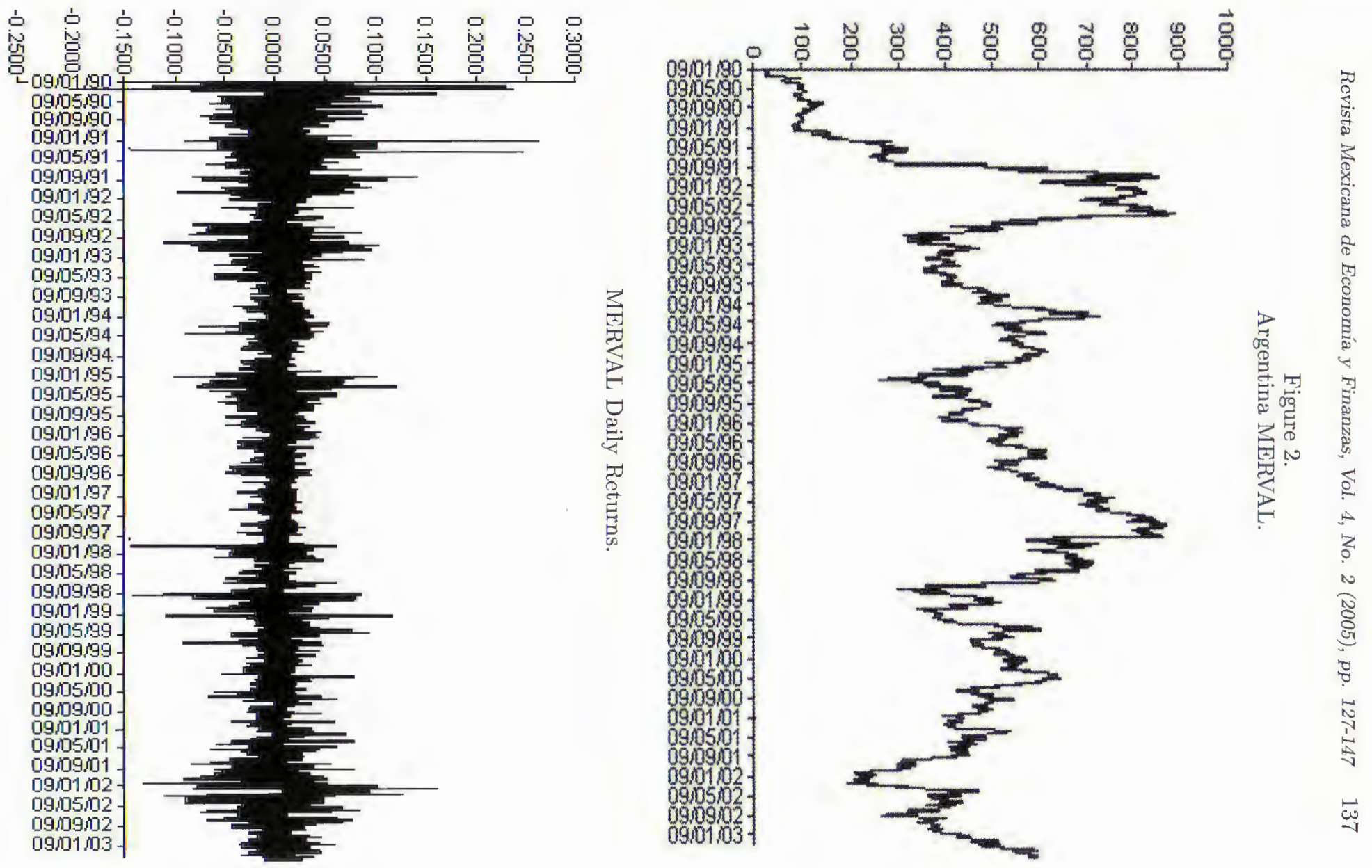


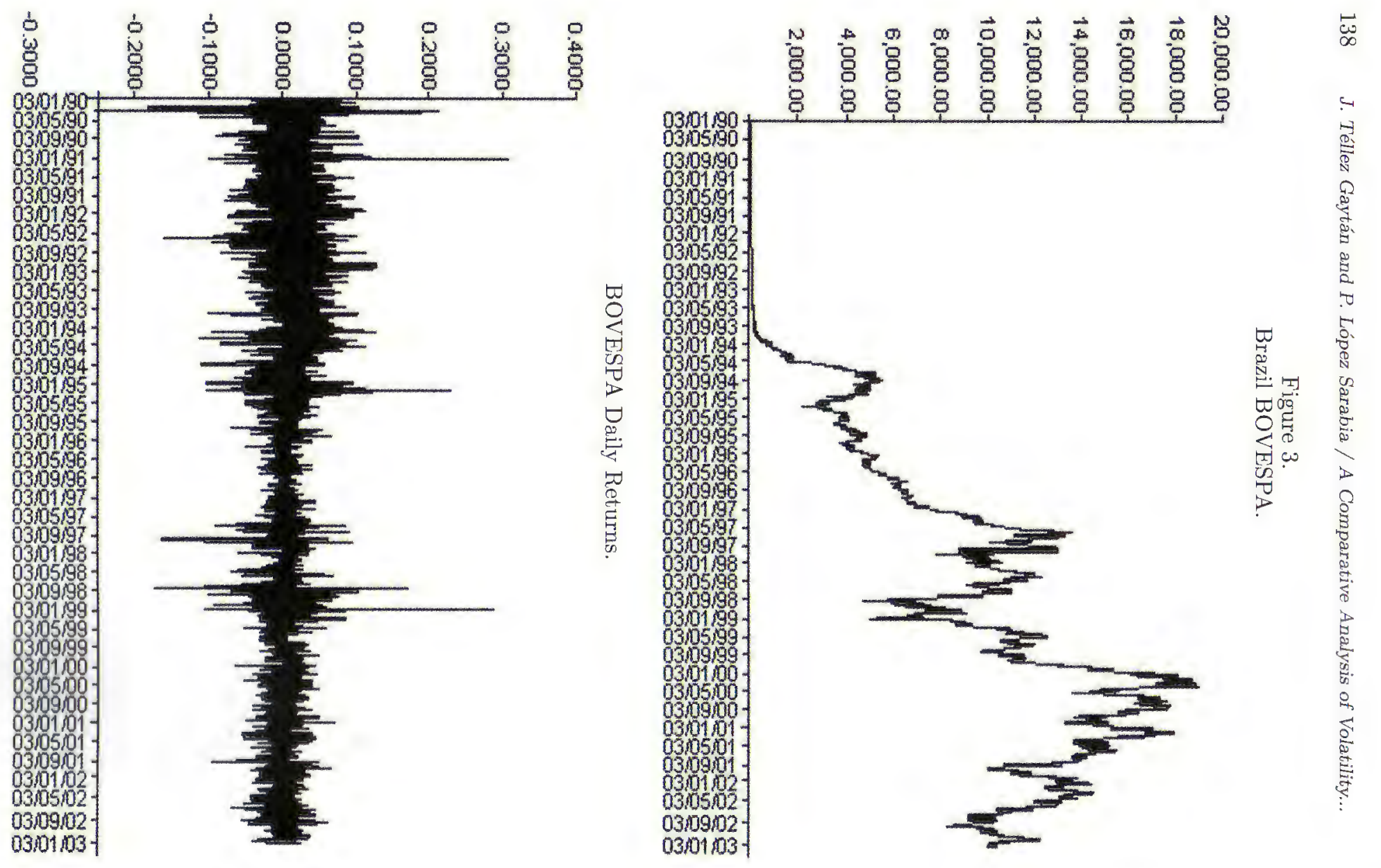



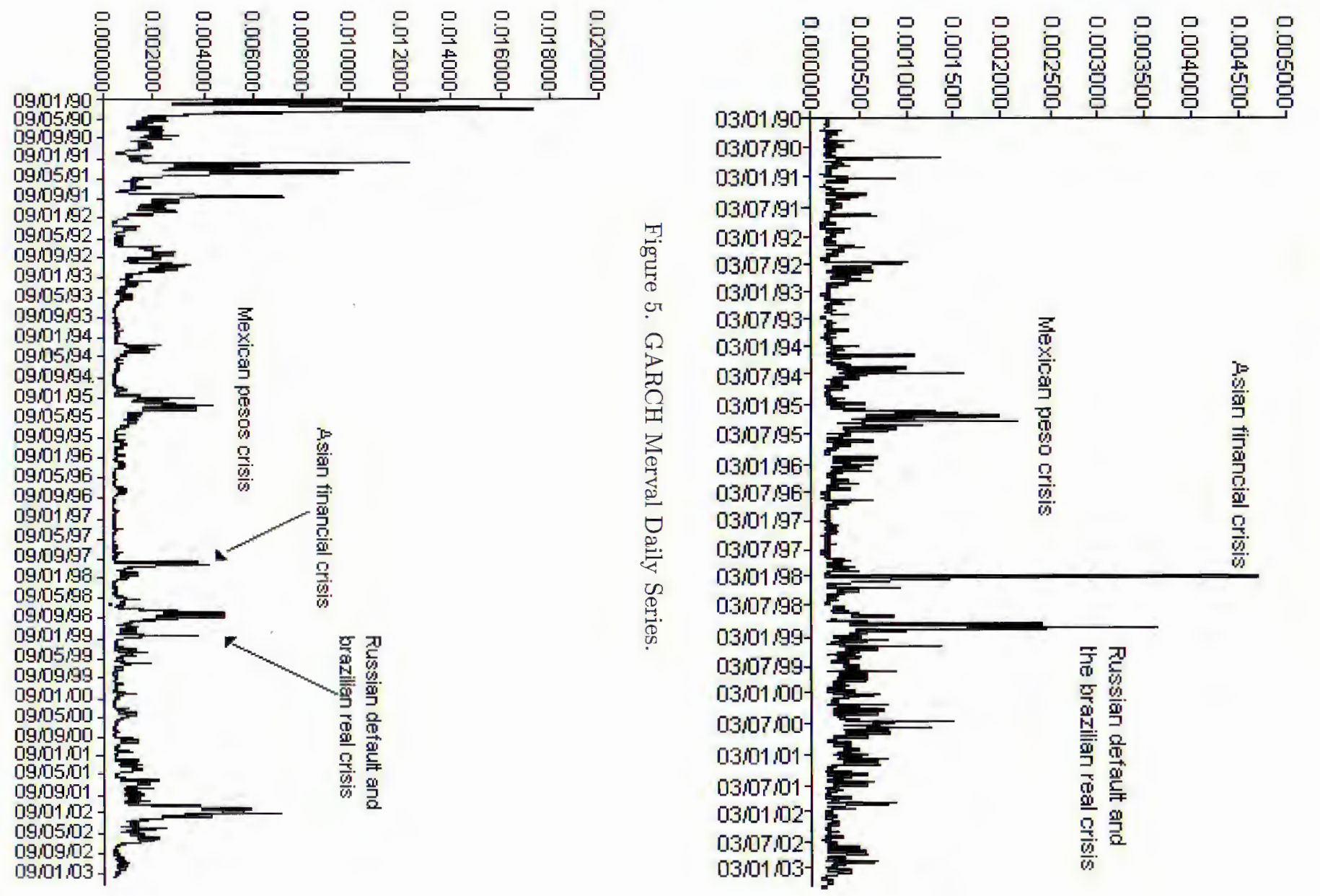

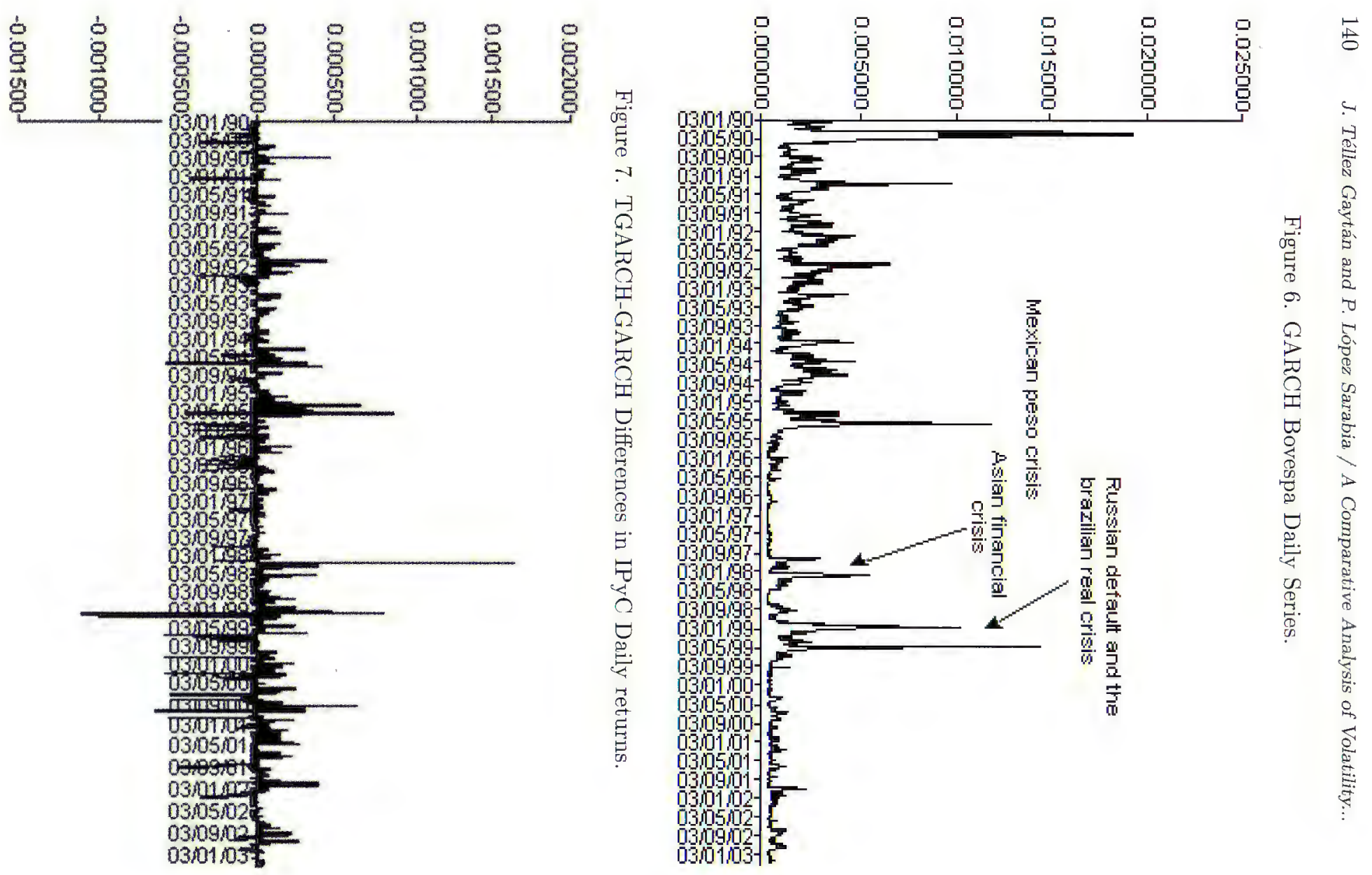
Figure 8. TGARCH-GARCH Differences in Merval Daily returns.

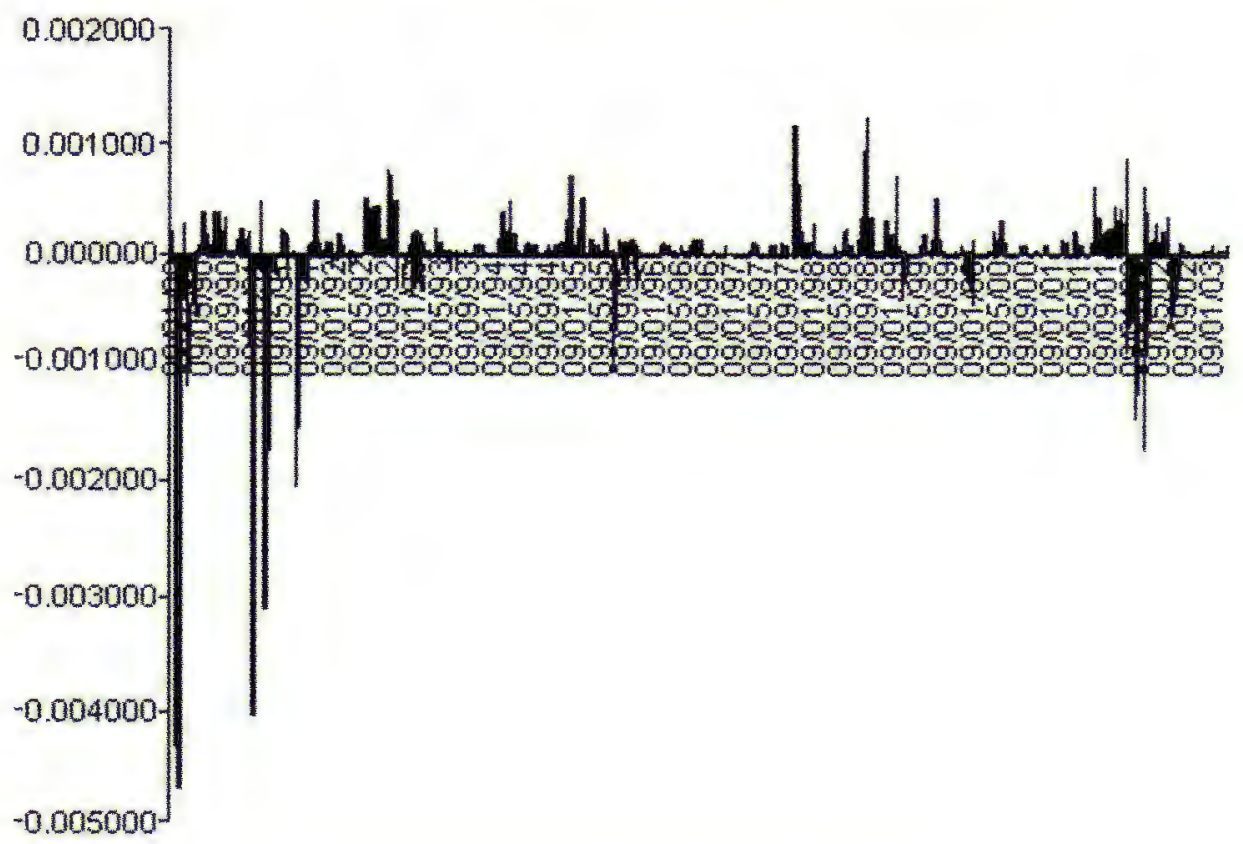

Figure 9. TGARCH-GARCH Differences in Bovespa Daily returns.

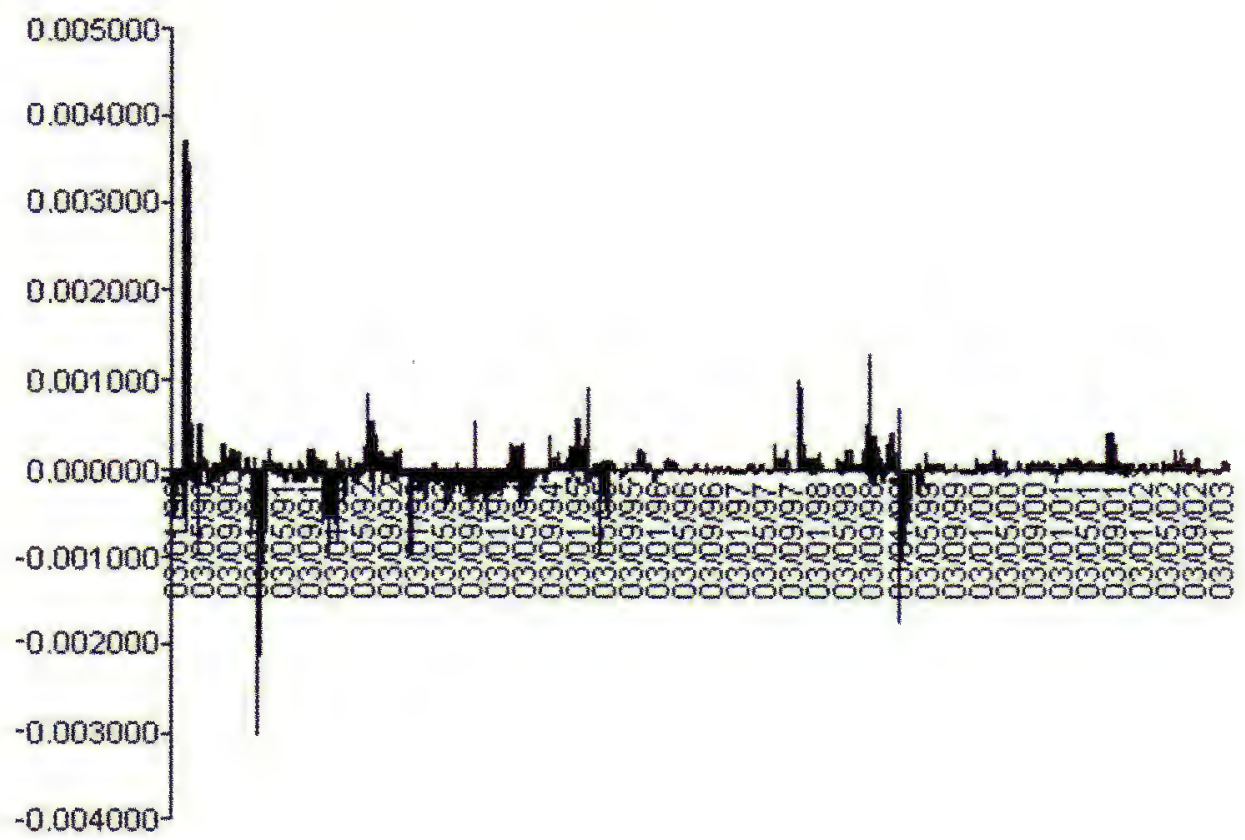




\section{B. Tables}

Table 1.

GARCH estimation equation on the IPyC Daily Returns.

Dependent Variable:RIPC

Method:ML - ARCH

Sample:13297

Included observations: 3297

Convergence achieved after 21 iterations

\begin{tabular}{ccccc}
\hline & Coefficient & Std. Error & z-Statistic & Prob. \\
C & 0.001414 & 0.000261 & 5.424411 & 0.000000 \\
\hline C & \multicolumn{2}{c}{ Variance Equation } & \\
ARCH(1) & $1.66 E-05$ & $1.88 E-06$ & 8.816056 & 0.000000 \\
GARCH(1) & 0.151895 & 0.009028 & 16.82435 & 0.000000 \\
& 0.797126 & 0.011654 & 68.39991 & 0.000000 \\
R-squared & -0.001266 & Mean dependent var & 0.000801 \\
Adjusted R-squared & -0.002178 & S.D. dependent var & 0.017214 \\
S.E. of regresion & 0.017233 & Akaike info criterion & -5.458084 \\
Sum squared resid & 0.977887 & Schwarz criterion & -5.450682 \\
Log likelihood & 9001.651 & Durbin-Watson stat & 1.749463 \\
\hline
\end{tabular}

Table 2.

GARCH estimation equation on the MERVAL Daily Returns.

Dependent Variable:RMERVAL

Method:ML - ARCH

Sample:13264

Included observations: 3264

Convergence achieved after 18 iterations

\begin{tabular}{ccccc}
\hline & Coefficient & Std. Error & z-Statistic & Prob. \\
C & 0.001003 & 0.000366 & 2.73838 & 0.0062 \\
\hline C & \multicolumn{2}{c}{ Variance Equation } & \\
\hline ARCH(1) & $1.24 E-05$ & $1.62 E-06$ & 7.678194 & 0.000000 \\
GARCH(1) & 0.132394 & 0.00746 & 17.74683 & 0.000000 \\
& $8.58 E-01$ & 0.007042 & 121.7977 & 0.000000 \\
R-squared & -0.000003 & Mean dependent var & 0.001061 \\
Adjusted R-squared & -0.000924 & S.D. dependent var & 0.031161 \\
S.E. of regresion & 0.031176 & Akaike info criterion & -4.570226 \\
Sum squared resid & 3.168472 & Schwarz criterion & -4.562762 \\
Log likelihood & 7462.608 & Durbin-Watson stat & 1.757803 \\
\hline
\end{tabular}


Table 3.

GARCH estimation equation on the BOVESPA Daily Returns.

Dependent Variable:RBOVESPA

Method:ML - ARCH

Sample:13248

Included observations: 3248

Convergence achieved after 18 iterations

\begin{tabular}{ccccc}
\hline & Coefficient & Std. Error & z-Statistic & Prob. \\
C & 0.00244 & 0.000419 & 5.824281 & 0.000000 \\
\hline C & $1.18 E-05$ & $2.22 E-06$ & 5.284722 & 0.000000 \\
ARCH(1) & 0.138531 & 0.008845 & 15.66262 & 0.000000 \\
GARCH(1) & 0.859257 & 0.008507 & 101.01 & 0.000000 \\
& & & \\
R-squared & -0.003163 & Mean dependent var & 0.004402 \\
Adjusted R-squared & -0.004091 & S.D. dependent var & 0.034896 \\
S.E. of regresion & 0.034968 & Akaike info criterion & -4.266622 \\
Sum squared resid & 3.966566 & Schwarz criterion & -4.259127 \\
Log likelihood & 6932.994 & Durbin-Watson stat & 1.771405 \\
\hline
\end{tabular}

Table 4.

TGARCH estimation equation on the IPyC Daily Returns.

Dependent Variable:RIPC

Method:ML - ARCH

MARQUARDT

Sample:13297

Included observations:3297

Convergence achieved after 15 iterations

Bollerslev-Wooldrige robust standard errors \& covariance

\begin{tabular}{ccccc}
\hline & Coefficient & Std. Error & z-Statistic & Prob. \\
C & 0.001013 & 0.000248 & 4.078823 & 0.000000 \\
\hline C & \multicolumn{2}{c}{ Variance } & Equation & \\
\hline ARCH(1) & $1.49 E-05$ & $2.96 E-06$ & 5.030027 & 0.000000 \\
(RESID $<0)^{*}$ ARCH(1) & 0.041524 & 0.013674 & 3.036717 & 0.002400 \\
GARCH(1) & 0.181558 & 0.03433 & 5.288674 & 0.000000 \\
& 0.821896 & 0.023819 & 34.50607 & 0.000000 \\
R-squared & -0.000152 & Mean dependent var & 0.000801 \\
Adjusted R-squared & -0.001367 & S.D. dependent var & 0.017214 \\
S.E. of regresion & 0.017226 & Akaike info criterion & -5.492178 \\
Sum squared resid & 0.976799 & Schwarz criterion & -5.482926 \\
Log likelihood & 9058.856 & Durbin-Watson stat & 1.751412 \\
\hline
\end{tabular}


Table 5.

TGARCH estimation equation on the MERVAL Daily Returns.

Dependent Variable:RMERVAL

Method:ML - ARCH

Sample: 13264

Included observations: 3264

Convergence achieved after 19 iterations

Bollerslev-Wooldrige robust standard errors \& covariance

\begin{tabular}{|c|c|c|c|c|}
\hline $\mathrm{C}$ & $\begin{array}{c}\text { Coefficient } \\
0.000491\end{array}$ & $\begin{array}{c}\text { Std. Error } \\
0.00035\end{array}$ & $\begin{array}{c}\text { z-Statistic } \\
1.402314\end{array}$ & $\begin{array}{c}\text { Prob. } \\
0.16080\end{array}$ \\
\hline \multicolumn{5}{|c|}{ Variance Equation } \\
\hline $\mathrm{C}$ & $1.17 E-05$ & $3.03 E-06$ & 3.853254 & 0.0001 \\
\hline $\operatorname{ARCH}(1)$ & 0.084935 & 0.022453 & 3.782851 & 0.0002 \\
\hline$(\mathrm{RESID}<0)^{*} \mathrm{ARCH}(1)$ & 0.093547 & 0.02969 & 3.150846 & 0.0016 \\
\hline $\operatorname{GARCH}(1)$ & 0.86033 & 0.017661 & 48.71404 & 0.0000 \\
\hline R-squared & -0.000334 & \multicolumn{2}{|c|}{ Mean dependent var } & 0.001061 \\
\hline Adjusted R-squared & -0.001561 & \multicolumn{2}{|c|}{ S.D. dependent var } & 0.031161 \\
\hline S.E. of regresion & 0.031186 & \multicolumn{2}{|c|}{ Akaike info criterion } & -4.581873 \\
\hline Sum squared resid & 3.169518 & \multicolumn{2}{|c|}{ Schwarz criterion } & -4.572542 \\
\hline Iog likelihood & 7482.616 & \multicolumn{2}{|c|}{ Durbin-Watson stat } & 1.757223 \\
\hline
\end{tabular}

Table 6.

TGARCH estimation equation on the BOVESPA Daily Returns.

Dependent Variable:RBOVESPA

Method:ML - ARCH

Sample: 13248

Included observations: 3248

Convergence achieved after 21 iterations

Bollerslev-Wooldrige robust standard errors \& covariance

\begin{tabular}{ccccc}
\hline & Coefficient & Std. Error & z-Statistic & Prob. \\
C & 0.002091 & 0.000404 & 5.173872 & 0.000000 \\
\hline C & \multicolumn{2}{c}{ Variance Equation } & & \\
\hline ARCH $(1)$ & $1.03 E-05$ & $2.68 E-06$ & 3.833016 & 0.000100 \\
(RESID $<0)^{*} \mathrm{ARCH}(1)$ & 0.110667 & 0.016445 & 6.729523 & 0.000000 \\
GARCH(1) & 0.057438 & 0.02679 & 2.144021 & 0.032000 \\
& 0.86271 & 0.013652 & 63.19407 & 0.000000 \\
R-squared & & & & \\
Adjusted R-squared & -0.004385 & Mean dependent var & 0.004402 \\
S.E. of regresion & -0.005624 & S.D. dependent var & 0.034896 \\
Sum squared resid & 0.034994 & Akaike info criterion & -4.270789 \\
Log likelihood & 3.971397 & Schwarz criterion & -4.26142 \\
& 6940.761 & Durbin-Watson stat & 1.76925 \\
\hline
\end{tabular}


Table 7.

EGARCH estimation equation on the IPyC Daily Returns.

Dependent Variable:RIPC

Method:ML - ARCH

Sample:13297

Included observations: 3297

Convergence achieved after 122 iterations

Bollerslev-Wooldrige robust standard errors \& covariance

\begin{tabular}{ccccc}
\hline & Coefficient & Std. Error & z-Statistic & Prob. \\
C & 0.000844 & 0.000257 & 3.286895 & 0.001000 \\
\hline C & -0.68344 & 0.130957 & -5.218806 & 0.000000 \\
\hline RES|/SQR [GARH](1) & 0.242036 & 0.036344 & 6.659573 & 0.000000 \\
RES/SQR $[$ GARCH](1) & -0.113641 & 0.02111 & -5.383391 & 0.000000 \\
EGARCH(1) & 0.939965 & 0.013695 & 68.63538 & 0.000000 \\
& & & & \\
R-squared & -0.000006 & Mean dependent var & 0.000801 \\
Adjusted R-squared & -0.001221 & S.D. dependent var & 0.017214 \\
S.E. of regresion & 0.017224 & Akaike info criterion & -5.488121 \\
Sum squared resid & 0.976657 & Schwarz criterion & -5.478869 \\
Log likelihood & 9052.168 & Durbin-Watson stat & 1.751667 \\
\hline
\end{tabular}

Table 8.

EGARCI estimation equation on the MERVAL Daily Returns.

Dependent Variable:RMERVAL

Method:ML - ARCH

Sample: 13264

Included observations:3264

Convergence achieved after 47 iterations

Bollerslev-Wooldrige robust standard errors \& covariance

\begin{tabular}{ccccc}
\hline & Coefficient & Std. Error & z-Statistic & Prob. \\
C & 0.00054 & 0.000368 & 1.465597 & 0.142800 \\
\hline C & \multicolumn{2}{c}{ Variance Equation } \\
\hline RES|/SQR [GARH](1) & 0.379406 & 0.06125 & -6.194436 & 0.000000 \\
RES/SQR[GARCH](1) & -0.054977 & 0.021079 & -2.608159 & 0.009100 \\
EGARCH(1) & 0.976332 & 0.006152 & 158.712 & 0.000000 \\
& & & \\
R-squared & -0.00028 & Mean dependent var & 0.001061 \\
Adjusted R-squared & -0.001507 & S.D. dependent var & 0.031161 \\
S.E. of regresion & 0.031185 & Akaike info criterion & -4.5747 \\
Sum squared resid & 3.169347 & Schwarz criterion & -4.56537 \\
Log likelihood & 7470.911 & Durbin-Watson stat & 1.757318 \\
\hline
\end{tabular}


Table 9.

EGARCH estimation equation on the BOVESPA Daily Returns.

Dependent Variable:RBOVESPA

Method:ML - ARCH

Sample: 13248

Included observations: 3248

Convergence achieved after 33 iterations

Bollerslev-Wooldrige robust standard errors \& covariance

\begin{tabular}{ccccc}
\hline & Coefficient & Std. Error & z-Statistic & Prob. \\
C & 0.002223 & 0.000395 & 5.632614 & 0.000000 \\
\hline C & \multicolumn{2}{c}{ Variance Equation } & & \\
\hline RES|/SQR $[$ GARH] $(1)$ & -0.337406 & 0.046103 & -7.318445 & 0.000000 \\
RES/SQR $[$ GARCH](1) & 0.269997 & 0.033456 & 8.070216 & 0.000000 \\
EGARCH(1) & -0.034161 & 0.01713 & -1.994161 & 0.046100 \\
& 0.982027 & 0.004446 & 220.8882 & 0.000000 \\
R-squared & & & & \\
Adjusted R-squared & -0.003902 & Mean dependent var & 0.004402 \\
S.E. of regresion & -0.00514 & S.D. dependent var & 0.034896 \\
Sum squared resid & 0.034986 & Akaike info criterion & -4.271733 \\
Log likelihood & 3.969486 & Schwarz criterion & -4.262365 \\
\hline
\end{tabular}

Table 10

GARCH coefficient values.

\begin{tabular}{cccccc}
\hline & $\alpha_{0}$ & $\alpha_{1}$ & $\beta_{1}$ & $\alpha_{1}+\beta_{1}$ & $\sigma^{2}$ \\
Mexico IPyC & $1.66 E-05$ & 0.151895 & 0.797126 & 0.949021 & 0.000326 \\
Argetina MERVAL & $1.24 E-05$ & 0.132394 & $8.58 E-01$ & 0.990147 & 0.001258 \\
Brasil BOVESPA & $1.18 E-05$ & 0.138531 & 0.859257 & 0.997788 & 0.005335 \\
\hline
\end{tabular}

Table 11

TGARCH coefficient values.

\begin{tabular}{ccccc} 
& $\alpha_{0}$ & $\alpha_{1}$ & $\gamma$ & $\beta_{1}$ \\
Mexico IPyC & $1.49 E-05$ & 0.041524 & 0.181558 & 0.821896 \\
& & & & \\
Argetina MERVAL & $1.17 E-05$ & 0.084935 & 0.093547 & 0.86033 \\
Brasil BOVESPA & $1.03 E-05$ & 0.110667 & 0.057438 & 0.86271 \\
\hline
\end{tabular}


Table 12

EGARCH coefficient values.

\begin{tabular}{ccccc}
\hline & $\omega$ & $\alpha$ & $\gamma$ & $\beta$ \\
Mexico IPyC & -0.68344 & 0.242036 & -0.113641 & 0.939965 \\
& & & & \\
Argetina MERVAL & -0.379406 & 0.267969 & -0.054977 & 0.976332 \\
& & & & \\
Brasil BOVESPA & -0.337406 & 0.269997 & -0.034161 & 0.982027 \\
\hline
\end{tabular}

\section{References}

Aggarwal, R., C. Inclan, and R. Leal (1999). Volatility in Emerging Stock Markets. Journal of Financial and Quantitative Analysis, 34.

Apergis, N. and S. Eleptheriou (2001). Stock Returns and Volatility: Evidence from the Athens Stock Market Index. Journal of Economics and Finance, 25, pp. 50-61.

Bollerslev, T. (1986). Generalized Autoregressive Conditional Heteroskedasticity. Journal of Econometrics, pp. 307-327.

Brooks, C. (2002). Introductory Econometrics for Finance. Cambridge University Press.

Edwards, S. and R. Susmel (2000). Volatility Dependence and Contagion in Emerging Equity Markets. NBER Working Paper

Engel, R. (2001). GARCH 101: The Use of ARCH/GARCH Models in Applied Econometrics. Journal of Economics Perspectives, 15, pp. 157-168.

Forbes, K. and R. Rigobon (1999). No Contagion, only Interdependence: Measuring Stock Market Co-Movements. NBER Working Paper 7267.

Johnston, K. and E. Scott (2000). GARCH Models and the Stochastic Process Underlying Exchange Rate Price Changes. Journal of Financial and Strategy Decisions, 13, pp. 13-24.

Hernandez, P. and P. Robins (2002). An Application of ARCH and ARCH-M Models to Study Inflation in Mexico from 1978 to 1999. Mexican Journal of Economics and Finance, 1, pp. 169-186.

Pagan, A. and G. Schwert (1990). Alternative Models for Conditional Stock Volatility. Journal of Econometrics, 45, pp. 267-290.

Patel, S. and A. Sarkar (1998). Stock Market Crises in Developed and Emerging Markets. Federal Reserve Bank of New York.

Reinhard, P. and A. Lunde (2001). A Comparison of Volatility Models: Does anything Beat a GARCH(1,1)?. Centre for Analytical Finance, University of Aarhus, Aarhus School of Business, Working Paper Series No. 84.

Vilariño, A. (2001). Turbulencias financieras y riesgos de mercado. Pearson Education. 